BMJ Open Diabetes Research \& Care

\section{Improved diabetes control among low- income Mexican Americans through community-clinical interventions: results of an RCT}

To cite: Reininger BM, Lee $\mathrm{M}$, Hessabi M, et al. Improved diabetes control among lowincome Mexican Americans through community-clinical interventions: results of an RCT. BMJ Open Diab Res Care 2020;8:e000867. doi:10.1136/ bmjdrc-2019-000867

- Additional material is published online only. To view please visit the journal online (http://dx.doi.org/10.1136/ bmjdrc-2019-000867).

Received 18 October 2019 Revised 20 February 2020 Accepted 15 March 2020
Check for updates

(C) Author(s) (or their employer(s)) 2020. Re-use permitted under CC BY-NC. No commercial re-use. See rights and permissions. Published by BMJ.

For numbered affiliations see end of article.

Correspondence to Dr Belinda M Reininger; Belinda.M.Reininger@uth. tmc.edu

\section{ABSTRACT}

Introduction This randomized controlled trial investigated community-clinical intervention strategies for a Mexican American population who had not demonstrated control of their diabetes. We tested a control program (Salud y Vida 1.0) supporting diabetes management versus an enhanced version (Salud y Vida 2.0) for reductions in HbA1c at 12 months.

Research design and methods Adults with uncontrolled diabetes $(n=353)$ were enrolled if they had an $\mathrm{HbA} 1 \mathrm{c} \geq 9.0 \%$ during a program or doctor's visit between 6 and 36 months of their receipt of SyV 1.0 services, were patients at one of two clinics in local counties, and had an $\mathrm{HbA} 1 \mathrm{c} \geq 8.0 \%$ at SyV 2.0 baseline enrollment. The control and intervention arms were coordinated by community health workers and the intervention arm included the control program enhanced with medication therapy management; behavioral health services; peer-led support groups; and additional community-based lifestyle programs also open to the family.

Results At 12 months, both study arms improved $\mathrm{HbA1c}$ (mean, $(\mathrm{Cl})$, Control $(-0.47(-0.74$ to -0.20$))$ and intervention $(-0.48(-0.76$ to -0.19$))$. The intervention group maintained $\mathrm{HbA} 1 \mathrm{c}$ levels after month 6 , whereas control group $\mathrm{HbA1c}$ levels slightly increased (adjusted mean from $9.83 \%$ at month $6 \%-9.90 \%$ at month 12 ). Also, $\mathrm{HbA1c}$ was examined by level of participant engagement. The high engagement group showed a decreasing trend over the study period, while control and lower engagement groups failed to maintain HbA1c levels at month 12. Conclusions Improved $\mathrm{HbA} 1 \mathrm{C}$ was found among a population that had not demonstrated diabetes management prior; however, mean $\mathrm{HbA} 1 \mathrm{c}$ values were above clinical guideline recommendations. The randomized control trial findings provide additional evidence that extended time and intervention supports may be needed for populations experiencing inequities in social determinants of health.

Trial registration number NCT04035395.

\section{INTRODUCTION}

Managing diabetes over time is essential for avoiding poor health outcomes, but is difficult because it involves a number of daily

\section{Significance of this study}

What is already known about this subject?

- Managing diabetes over time is difficult because it involves multiple behaviors.

- Many people do not successfully control their diabetes and Mexican Americans are disproportionally burdened with the complications of diabetes.

- While there are some examples of interventions that support long-term maintenance of diabetes control, fewer options have been tested in low-income populations with inequities in the social determinants of health, like Mexican Americans.

What are the new findings?

- We show positive results in diabetes maintenance for low-income Mexican American populations in two arms of our intervention trial.

How might these results change the focus of research or clinical practice?

- Interventions that provide continuum of care options to address medical needs and inequities in social determinants of health are related to better diabetes maintenance among Mexican Americans, a population burdened with health disparities, and address a service gap experienced by this population.

behaviors that must be achieved routinely and over a lifetime. The American Diabetes Association recommends balancing food intake with exercise and medicine, weight loss and as recommended by a physician, monitoring blood glucose levels. ${ }^{1}$ Many of the 30.3 million adults with diagnosed diabetes $(9.4 \%$ of the US population), including the 7.2 million who are undiagnosed (23.8\% of people with diabetes),${ }^{2}$ do not fully manage their disease. Social determinants of health create barriers for individuals to implement these health promoting behaviors. ${ }^{34}$ Mexican American populations are disproportionally burdened 
with many of the common and complex complications of diabetes including death, kidney failure, amputations, adult-onset blindness, and heart attack. ${ }^{25-7}$

There are evidence-based chronic care management approaches shown to significantly improve disease outcomes short-term including for individuals with diabetes; ${ }^{8} 9$ yet questions remain about intervention support options delivered over time in a cost effective manner for individuals who struggle to manage their disease, particularly those burdened with social determinants of health. ${ }^{10}$ Strong evidence exists that Diabetes Self-Management Education and Support (DSME) is regarded as foundational for helping individuals with diabetes employ the daily activities and choices necessary to manage the disease properly. ${ }^{11}$ However, long-term maintenance of diabetes control is still an issue for some individuals even after DSME courses are completed. ${ }^{12}$

Inequities found in the social determinants of health add to the struggles of diabetes management including low-income,${ }^{13}$ inadequate housing, ${ }^{14}$ behavioral health needs, ${ }^{15}$ and lack of health insurance. ${ }^{16}$ In addition, lack of resources/support for medications and doctor visits, ${ }^{17}$ transportation, ${ }^{4}$ day labor jobs/choice between work and doctor visits, ${ }^{18}$ culture and language capabilities $^{19}$ are other barriers to diabetes self-management found among Mexican American populations. Community health workers are effective in delivering interventions that improve diabetes management by providing language interpretation; helping to address barriers to care including communication with providers; and advocating for their participants to receive culturally relevant healthcare services. ${ }^{201}$ In addition, people with diabetes are 2-3 times more likely to have depression than people without diabetes, and less than $50 \%$ of people with diabetes who have depression get diagnosed and treated. Integrating behavioral health and stress management treatment into diabetes programs is key to addressing behavioral health and diabetes. ${ }^{22}$ Insurance coverage has been found to be associated with decreased medical costs from complications among low-income individuals with diabetes who obtained health coverage through the Affordable Care Act. ${ }^{23}$ Individuals who are burdened with health disparities, especially Mexican American populations, may benefit from intervention support to manage diabetes over extended period of times, but few intervention options have been investigated in an extended timeframe. ${ }^{24}$ Without additional strategies to address diabetes long-term management, the financial and lost productivity costs from diabetes will continue to escalate beyond the current estimates of $\$ 237$ billion a year in medical costs and $\$ 90$ billion a year in lost productivity costs. ${ }^{25}$

This study examined the addition of communityclinical intervention strategies, which had shown evidence to improve outcomes in other studies, to a base chronic care management program in a randomized control trial (RCT) design. This allowed for comparison of two avenues of care on improved diabetes control for individuals with diabetes who had already been in an intervention for at least 6 months but had showed no consistent improvement in their HbAlc at the point of study enrollment. Individuals enrolled in the study were primarily low-income, uninsured Mexican Americans with diabetes. The main research question was: are participants who receive Salud y Vida 2.0 (SyV 2.0) more likely to reduce HbAlc after 12 months compared with participants who receive Salud y Vida 1.0 (SyV 1.0) (control)?

\section{METHODS}

\section{General description}

The Rio Grande Valley of Texas, located on the northern bank of the Rio Grande River that separates the USA from Mexico, is home to more than 1.2 million residents, representing about $5 \%$ of Texas' general population. ${ }^{26}$ The SyV 2.0 program works with the system of healthcare in this area reaching predominantly Mexican American, low-income, underserved individuals with chronic disease rates and related mortality that exceed those in most other regions of the state and the nation. Based on a cohort study of Mexican American adults from this region between 2003 to 2008 called the Cameron County Hispanic cohort, researchers estimated diabetes prevalence to be $31 \%$ and $81 \%$ of the population were either obese $(49 \%)$ or overweight $(32 \%) .{ }^{27}$ Residents in this region suffer from disproportionate health disparities that stem from extreme poverty ( $40 \%$ of families live below federal poverty line), lower levels of educational attainment, ${ }^{26}$ and inadequate access to basic healthcare needs. $^{27}$

University of Texas Health Science Center at Houston, School of Public Health (UTHealth SPH) and its partners implemented SyV 2.0 in September 2016. The free of charge, evidence-based chronic care management SyV 2.0 program aimed to expand the existing SyV 1.0 program. The original program ( $\mathrm{SyV} 1.0)$, which is the control arm in this study, was designed to assist individuals with uncontrolled diabetes. The program is modeled after an expanded Wagner's Chronic Care Management model ${ }^{92829}$ and relies on a cross-disciplinary team including healthcare providers, social workers, and other clinic personnel alongside representatives from community-based organizations, including community health workers (CHWs), to address the individualized needs of the patient which go beyond basic primary care, such as behavioral health, nutrition, medication compliance, transportation, financial support, and other ancillary services.

The SyV 1.0 program has helped nearly $60 \%$ of its 3500 participants gain control of their diabetes $(\mathrm{HbAlc}<9.0)$ within 12 months. Some participants, however, still struggled with the disease due to social determinants of health including behavioral health, primary healthcare access issues, and other social and environmental barriers to making lifestyle changes. 


\section{Trial design}

The study was a two-arm randomized control trial to compare intervention participants receiving an enhanced delivery of chronic care management including behavioral health with control participants receiving the base program. Participants enrolled in the study were followed for 12 months. The study was approved by the University of Texas Health Science Center at Houston Committee for the Protection of Human Subjects (protocol reference number HSC-SPH-16-0044) and registered with clinicaltrials.gov (NCT04035395).

\section{Study population (participants)}

Eligibility criteria: All SyV 1.0 participants were eligible for the intervention study after they had been enrolled in SyV 1.0 for a minimum of 6 months and a maximum of 36 months. Participants recruited for SyV 2.0 were also required to (I) be an active patient of one of two partner clinics (confirmed by clinic staff), (II) reside in Cameron or Willacy Counties of Texas, (III) have an $\mathrm{HbAlc} \geq 9.0 \%$ at any quarterly visit or doctor's visit between 6 and 36 months of SyV 1.0 services, and (IV) have an $\mathrm{HbAlc} \geq 8.0 \%$ at SyV 2.0 baseline enrollment.

\section{Control arm}

Participants randomized to the control group continued to participate in the $\mathrm{SyV} 1.0$ program. All participants in the SyV 1.0 program were individuals with uncontrolled diabetes when they began the program. To achieve diabetes control, the $\mathrm{SyV} 1.0$ coalition of providers created coordinated care options in the clinic, community, and home. These participants were voluntarily enrolled in the program by a registered nurse, licensed vocational nurse, or a research assistant and assigned a CHW, who conducted follow-up home visits and phone calls for the duration of the program. The CHW provided ongoing support to the individual through home visits and ensured they were enrolled in a 6-week long diabetes self-management course. Also, the participants may have received referrals to the mental health authority agency if necessary (eg, based on administration of the Patient Health Questionnaire-9 (PHQ-9)) and quarterly home visits including feedback on HbAlc levels. During the home visits, CHWs worked with the participant to set goals and identify strategies of change using motivational interviewing techniques. The program worked closely with healthcare providers to address the needs of the patient and in some cases included providing brief financial support for items such as medications. SyV 1.0 participants also received an information session as per their treatment plan and/or a onetime mailing of information about the importance of following their treatment plan.

\section{Intervention arm}

Participants randomized to the intervention group received the SyV 2.0 program, which in addition to $\mathrm{SyV}$ 1.0 services, included: (1) medication therapy management (MTM) services comprised of individual sessions with a pharmacist to review and refine medications; (2) behavioral health services and its care coordination (BHS) for participants who did not have a qualifying diagnosis for services with the mental health authority, but needed behavioral health support for anxiety or depression; coordinated with primary care providers; (3) peer-led support groups (PLSG) for participants and family; and (4) community-based lifestyle programs for participants and family, which included healthy cooking classes (La Cocina Alegre/The Happy Kitchen).

\section{Collection of data}

Eligible participants who agreed to the study were met by trained university research staff at a single community reference laboratory. The laboratory staff obtained $2 \mathrm{~mL}$ of blood to assess Hemoglobin A1c (HbAlc) and $3 \mathrm{~mL}$ of blood to conduct a lipid panel for other secondary outcome measures. The research staff obtained anthropometric measures and survey data for other outcomes not reported. The data collection visits occurred at baseline, 6 months, and 12 months. Demographic and past program outcomes were obtained from our program database, Wellcentive, to generate potential study participants and for those consented these data were entered into the Research Electronic Data Capture (REDCap). ${ }^{30}$ Both systems are HIPPA protected and designed to safely store protected health information. All data were managed in REDCap.

\section{Recruitment/retention/attrition}

Study participants were recruited from two clinic sites that were partners on the Salud y Vida program and had been referring their patients to the SyV program (control group description). As this study was seeking participants who had not shown improvement in their first 6-36 months with the program, there were approximately 1200 active SyV 1.0 participants among the clinic partners, of which 423 were eligible to participate in SyV 2.0. Most of the participants enrolled in the study were female $(70.5 \%)$, Mexican American $(92.1 \%)$, and spoke Spanish as their primary language $(67.7 \%)$. The average participant age was 51.5 years. Over half of study participants were unemployed $(61.4 \%)$, uninsured $(69.4 \%)$, and made $\$ 1000$ or less a month in their household $(74.1 \%)$. Over half of participants were married $(53.2 \%)$ and did not graduate from high school (59.1\%).

Enrollment into the study occurred between September 2016 and May 2017. A total of 353 participants were enrolled, with 176 randomized to the intervention group and 177 to the control group. At 12 months, the study retained $84 \%$ of the intervention group and $82 \%$ of the control group. There was no difference in the proportion of retained and lost in each study group.

\section{Randomization}

Eligible participants were randomized using a computerized minimization randomization schedule based on dynamic random allocation algorithm for minimization 


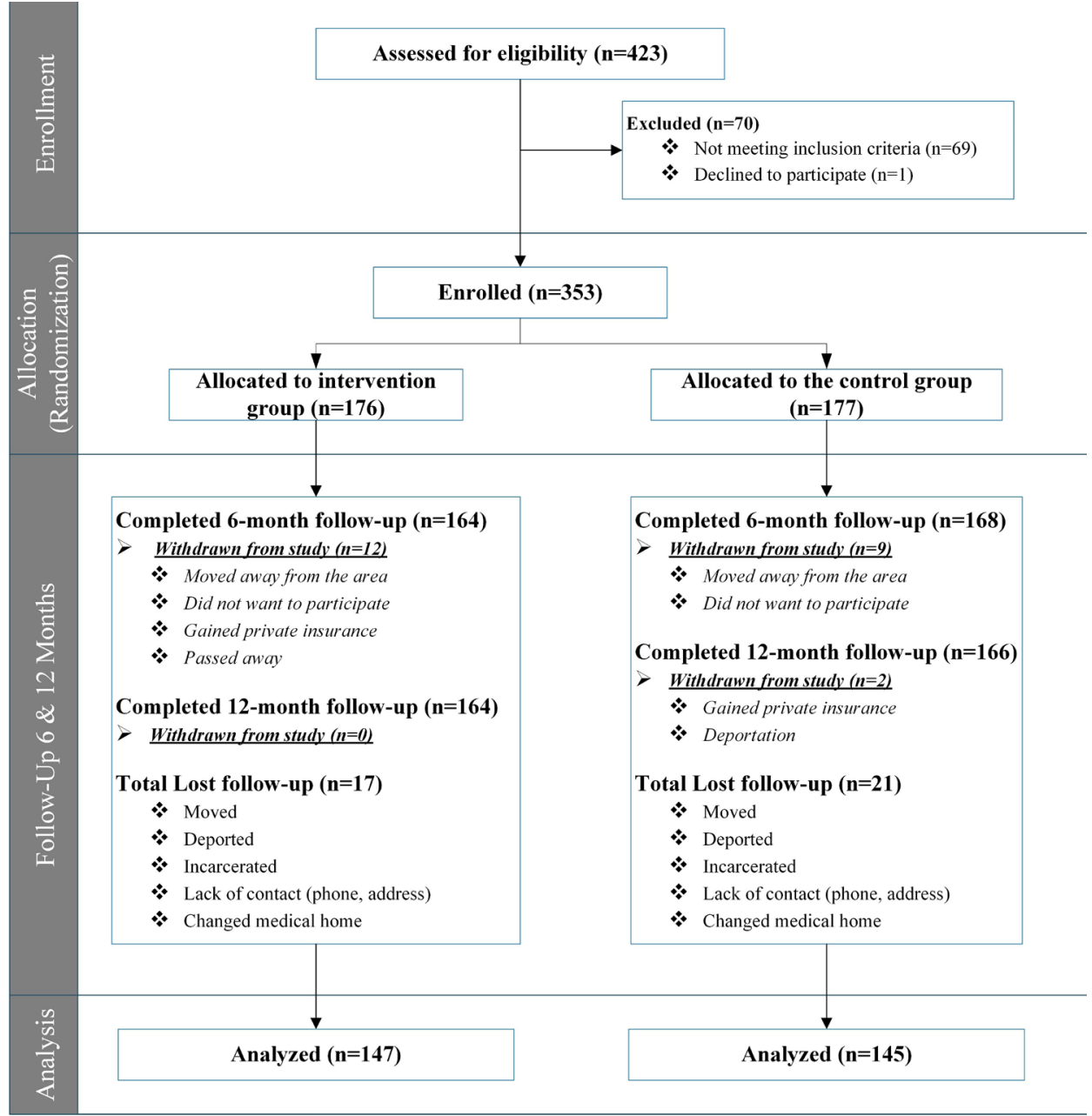

of unbalanced intervention assignment. Minimization randomization is one of the adaptive randomization procedures $^{31}$ that allocates participants to study arms based on similar characteristics already randomized to best balance the study arms across all stratification variables. Minimization algorithm was programmed using $\mathrm{R}^{32}$ to balance the two study arms with respect to participants' demographics, specifically age and sex. A random allocation of $\mathrm{p}=0.67-0.80$ was used in the minimization algorithm. Implementation of the computerized minimization randomization schedule was continuously monitored by two statisticians to ensure balance.

A patient flow diagram following the CONSORT structure is presented in figure 1 . This diagram depicts the study process from assessment of eligibility to enrollment and group selection, ending with retention and analysis. Sample sizes are provided throughout to show timing of participant attrition. Qualitative reasons for any ineligibility, withdrawal, or lost-to-follow-up are provided where applicable. In the "enrollment" stage, 70 participants who were excluded did not meet one or more of the eligibility criteria, mainly based on HbAlc at baseline. In the "follow-up" stage, those participants categorized as "lost to follow-up" did not complete an assessment at that time point but did not formally withdraw from the study. Due to the lack of official withdrawal from the study, those who were lost to follow-up at 6 months remained in the study and were still eligible to complete a 12-month assessment.

\section{Statistical analysis}

A total of 353 study participants were assigned randomly into two groups: the intervention group $(n=176)$ and the control group $(n=177)$. After attrition from dropouts or loss to follow-up, we analyzed data from the remaining 292 participants. Among them, 145 participants are in the control group and 147 are in the intervention group. The intent-to-treat analyses were performed using both univariable and multivariable longitudinal linear regression models based on generalized estimating equation method that accounts for potential correlations of repeated measures within a participant over time. We evaluated whether the effect of the intervention on HbAlc level changed over time by testing interactions between intervention group and time (follow-up month) which allow estimating the intervention effect on HbAlc at each follow-up month separately. Potential confounding factors including age, sex and race were examined and 
Table 1 Baseline demographic characteristics by study group $(n=292)$

\begin{tabular}{|c|c|c|c|}
\hline Variable & Control, n=145 (49.9\%) & Intervention, $\mathrm{n}=147$ (51.1\%) & $P$ value \\
\hline Age, mean (SD) & $52.08(9.24)$ & $51.08(9.00)$ & 0.78 \\
\hline Female, n (\%) & $110(75.86)$ & $105(71.43)$ & 0.43 \\
\hline Mexican American-White, $\mathrm{n}(\%)$ & 139 (97.89) & $135(95.07)$ & 0.33 \\
\hline Speak Spanish, n (\%) & $100(68.97)$ & $96(65.31)$ & 0.53 \\
\hline Employment & & & 0.35 \\
\hline Not employed, n (\%) & $90(62.94)$ & $91(63.19)$ & \\
\hline Employed, n (\%) & $21(14.64)$ & $14(9.72)$ & \\
\hline Other, n (\%) & $32(22.38)$ & $39(27.08)$ & \\
\hline Married, n (\%) & $77(53.47)$ & $73(50.69)$ & 0.72 \\
\hline Insurance, n (\%) & $41(31.30)$ & $38(29.01)$ & 0.79 \\
\hline Education, completed high school, n (\%) & $58(40.56)$ & $57(39.04)$ & 0.81 \\
\hline SBP, mean (SD) & $134.53(19.30)$ & $135.36(19.77)$ & 0.72 \\
\hline DBP, mean (SD) & $78.86(12.78)$ & $79.50(12.54)$ & 0.66 \\
\hline Cholesterol level, mean (SD) & $191.64(47.81)$ & $195.15(50.69)$ & 0.54 \\
\hline Quality of life score, mean (SD) & $65.20(18.45)$ & $69.42(19.41)$ & 0.06 \\
\hline PHQ-9 score, mean (SD) & $5.94(5.76)$ & $4.71(5.43)$ & 0.06 \\
\hline Time since diagnosis, (years) (SD)* & $12.54(7.86)$ & $11.91(7.39)$ & 0.52 \\
\hline $\mathrm{HbA1C}$ per cent at baseline, mean (SD) & $10.31(1.34)$ & $10.26(1.34)$ & 0.99 \\
\hline
\end{tabular}

${ }^{*}$ Forty-six (15.8\%) of participants did not report diagnosis date and therefore removed from further analysis.

DBP, diastolic blood pressure; PHQ-9, Patient Health Questionnaire-9; SBP, systolic blood pressure.

addressed during development of the final longitudinal multivariable models. In addition to intent-to-treat analyses, we classified intervention participants into high and low engagement groups based on total number of visits of four types of intervention programs (MTM, BHS, PLSG, and La Cocina Alegre) in order to assess the effect of engagement levels on HbAlc. Intervention participants were broken down into two groups based on a median value: (1) high engagement group $(n=91)$ who received the minimum dose ( $\geq 2$ visits to a service and (2) low engagement group $(n=56)$ who did not receive the minimum dose ( $<2$ visits). Similar to intent-to-treat analyses, longitudinal multivariable interactive models were developed after controlling for potential confounders. SAS $9.4^{33}$ was used to perform all statistical analyses and statistical significance was assumed at the 0.05 level.

\section{RESULTS}

Baseline demographic characteristics by intervention group are presented in table 1 . We observed no significant differences in demographic variables as well as baseline $\mathrm{HbAlc}$ between the intervention and control groups. No significant difference was found between groups in systolic blood pressure, diastolic blood pressure, cholesterol levels, quality of life score, PHQ-9 score, and time since diagnosis.

Results from the intent-to-treat analysis are shown in table 2. Based on univariable longitudinal analysis (unadjusted model), intervention participants had a lower level of HbA1c over the entire follow-up period visits, though not statistically significant, compared with control participants. This positive intervention effect remained the same in multivariable longitudinal model (=adjusted model) that was adjusted for clinically/statistically relevant variables identified a priori: age, sex, preferred language, race, employment status, marital status, insurance status, and education. Though not statistically significant, we found the intervention effect on $\mathrm{HbAlc}$ slightly changed over time in both univariable and multivariable models (overall $\mathrm{p}$ value of interaction effect between study group and follow-up visit was $p>0.9$ for both models). For example, adjusted mean difference in $\mathrm{HbA1c}$ between intervention and control was -0.03 at 6 month and -0.08 at 12 months. The adjusted mean HbA1c levels over time by study group were estimated based on our final multivariable model and were plotted in online supplementary material, figure 2 , which shows lower HbAlc levels in the intervention group compared to the control groups over time. There was a significant decrease in HbAlc levels from baseline to 6 months follow-up visit for both intervention and control groups $(p<0.001)$, and the intervention group maintained their HbA1c levels after month 6, whereas HbA1c levels in the control group slightly increased (adjusted mean from $9.83 \%$ at month 6 to $9.90 \%$ at month 12 ).

In addition to intent to treat analyses, we evaluated the effect of the level of engagement in the program on HbAlc over time based on multivariable model after 
Table 2 Intervention effect on $\mathrm{HbA1c}$ levels over time based on intent to treat analysis using univariable and multivariable longitudinal linear regression models $(n=292)$

\begin{tabular}{|c|c|c|c|c|}
\hline \multirow[b]{2}{*}{ Variable } & \multicolumn{2}{|l|}{ Unadjusted model } & \multicolumn{2}{|l|}{ Adjusted $^{*}$ model } \\
\hline & Mean difference $(95 \% \mathrm{Cl})$ & $P$ value & Mean difference $(95 \% \mathrm{Cl})$ & $P$ value \\
\hline \multicolumn{5}{|l|}{ Intervention effect } \\
\hline \multicolumn{5}{|l|}{ Intervention vs Control at each month $\dagger$} \\
\hline At month 0 & $-0.08(-0.46$ to 0.31$)$ & 0.6942 & $-0.09(-0.42$ to 0.25$)$ & 0.6157 \\
\hline At month 6 & $-0.04(-0.46$ to 0.37$)$ & 0.8509 & $-0.03(-0.43$ to 0.37$)$ & 0.8693 \\
\hline At month 12 & $-0.05(-0.35$ to 0.26$)$ & 0.7604 & $-0.08(-0.52$ to 0.36$)$ & 0.7219 \\
\hline \multicolumn{5}{|l|}{ Time effect } \\
\hline \multicolumn{5}{|l|}{ Month 6 vs month 0 for each group $\dagger$} \\
\hline For control group & $-0.51(-0.75$ to -0.27$)$ & $<0.0001$ & $-0.54(-0.79$ to -0.30$)$ & $<0.0001$ \\
\hline For intervention & $-0.54(-0.80$ to -0.27$)$ & $<0.0001$ & $-0.49(-0.77$, to 0.22$)$ & 0.0005 \\
\hline \multicolumn{5}{|l|}{ Month 12 vs month 0 for each group $\dagger$} \\
\hline For control group & $-0.47(-0.74$ to -0.20$)$ & 0.0006 & $-0.47(-0.74$ to -0.20$)$ & 0.0006 \\
\hline For intervention & $-0.46(-0.72$ to -0.20$)$ & 0.0005 & $-0.48(-0.76$ to -0.19$)$ & 0.0011 \\
\hline Age (years) & - & - & $-0.02(-0.04$ to -0.01$)$ & 0.0059 \\
\hline Sex: female vs male & - & - & $-0.23(-0.60$ to 0.14$)$ & 0.2263 \\
\hline Language: Spanish vs other & - & - & $0.26(-0.13$ to 0.64$)$ & 0.1921 \\
\hline Mexican American: White vs other & - & - & $0.01(-0.49$ to 0.52$)$ & 0.9556 \\
\hline Employment & & & $0.35(-0.20$ to 0.91$)$ & 0.2061 \\
\hline Employed vs other & - & - & $0.06(-0.35$ to 0.47$)$ & 0.7590 \\
\hline Unemployed vs other & - & - & $-0.03(-0.37$ to 0.30$)$ & 0.8532 \\
\hline Marital status married vs other & - & - & $-0.01(-0.36$ to 0.34$)$ & 0.9664 \\
\hline Insurance yes vs no & - & - & $0.16(-0.21$ to 0.52$)$ & 0.4058 \\
\hline Education high school or higher vs other & - & - & $-0.02(-0.04$ to 0.01$)$ & 0.0059 \\
\hline
\end{tabular}

*Multivariable longitudinal linear regression model after adjusting for age, sex, preferred language, race, employment status, marital status, type of insurance, and years in school.

†Based on interactive models where interactions between study group and follow-up visit (month) were included and tested

controlling for potential confounders (table 3). Though not statistically significant, we found the intervention effect on HbAlc changed over time in multivariable model (overall $p$ value of interaction effect between level of engagement and follow-up visit was $\mathrm{p}=0.54$ ). The high engagement group who received the minimum dose had a slightly lower HbA1c level at month 6 (adjusted mean difference $=-0.01$ ) compared with the control group, but this difference was getting larger at month 12 (adjusted mean difference $=-0.11$ ), although not statistically significant. Compared with the low engagement group who did not receive the minimum dose, the high engagement group had a lower HbA1c level at month 12 (adjusted mean difference $=-0.04$ ), but this positive effect of the high engagement group was not found at month 6 . There was a decrease in HbA1c levels from baseline to 6 months for both groups (adjusted mean difference $=-0.37$ $(\mathrm{p}=0.09)$ for the high engagement, and $-0.58(\mathrm{p}=0.002)$ low engagement group). The adjusted mean $\mathrm{HbAlc}$ levels over time by engagement level were estimated based on adjusted multivariable model and were plotted in (see online supplementary material, figure 3). The high engagement group showed a consistent decreasing trend over the entire follow-up period, while the control and lower engagement group failed to maintain their HbAlc level at month 12.

We further looked at the four intervention programs separately. Since three programs had either a low number of visits (ie, PLSG and Cocina Alegre) or low number of approved referrals (ie, BHS), we conducted longitudinal regression analyses for 248 participants referred to the MTM program. Based on multivariable model after controlling for the potential confounders including demographic characteristics and insurance, high engagement of MTM ( $\geq 2$ visits) had lower HbAlc levels at month 6 (adjusted mean difference $=-0.10 ; \mathrm{p}=0.73$ ) compared with the control group, and this difference was getting larger at month 12 (adjusted mean difference $=-0.28 ; p=0.36$ ). The high engagement group showed a consistent decreasing trend over the entire follow-up period (adjusted mean difference from baseline to month $12=-0.87 ; \mathrm{p}=0.0001$ ), while the lower engagement group failed to maintain their HbAlc level at month 12 (adjusted mean difference from baseline to month $12=-0.41 ; \mathrm{p}=0.1299$ ) 
Table 3 Effect of engagement level ${ }^{\star}$ on $\mathrm{HbA} 1 \mathrm{c}$ levels over time based on multivariable longitudinal linear regression models $(\mathrm{n}=292)$

\begin{tabular}{|c|c|c|}
\hline \multirow[b]{2}{*}{ Variable } & \multicolumn{2}{|l|}{ Adjusted† model } \\
\hline & Mean difference $(95 \% \mathrm{Cl})$ & $P$ value \\
\hline \multicolumn{3}{|l|}{ Intervention effect } \\
\hline \multicolumn{3}{|l|}{ Low engagement vs control at each month $\ddagger$} \\
\hline At month 0 & $-0.17(-0.57$ to 0.24$)$ & 0.4219 \\
\hline At month 6 & $-0.20(-0.77$ to 0.37$)$ & 0.4940 \\
\hline At month 12 & $0.05(-0.53$ to 0.63$)$ & 0.8665 \\
\hline \multicolumn{3}{|l|}{ High engagement vs control at each month $\ddagger$} \\
\hline At month 0 & $-0.03(-0.43$ to 0.37$)$ & 0.8783 \\
\hline At month 6 & $0.08(-0.38$ to 0.53$)$ & 0.7471 \\
\hline At month 12 & $-0.16(-0.67$ to 0.34$)$ & 0.5272 \\
\hline \multicolumn{3}{|c|}{ High engagement vs low engagement at each month $\ddagger$} \\
\hline At month 0 & $0.14(-0.34$ to 0.61$)$ & 0.5756 \\
\hline At month 6 & $0.28(-0.36$ to 0.91$)$ & 0.3972 \\
\hline At month 12 & $-0.21(-0.85$ to 0.42$)$ & 0.5106 \\
\hline \multicolumn{3}{|l|}{ Time effect } \\
\hline \multicolumn{3}{|l|}{ Month 6 vs month 0 for each group $\ddagger$} \\
\hline For control group & $-0.55(-0.79$ to -0.30$)$ & $<0.0001$ \\
\hline For high engagement group & $-0.44(-0.80$ to -0.08$)$ & 0.0177 \\
\hline For low engagement group & $-0.58(-1.01$ to -0.15$)$ & 0.0087 \\
\hline \multicolumn{3}{|l|}{ Month 12 vs month 0 for each group $\ddagger$} \\
\hline For control group & $-0.48(-0.76$ to -0.19$)$ & 0.0011 \\
\hline For high engagement group & $-0.61(-0.96$ to -0.26$)$ & 0.0007 \\
\hline For low engagement group & $-0.26(-0.67$ to 0.15$)$ & 0.2120 \\
\hline Age (years) & $-0.02(-0.04$ to -0.01$)$ & 0.0095 \\
\hline Sex: female vs male & $-0.23(-0.57$ to 0.10$)$ & 0.1894 \\
\hline Language Spanish vs other & $0.34(-0.05$ to 0.72$)$ & 0.0812 \\
\hline Mexican American: White vs other & $0.29(-0.24$ to 0.83$)$ & 0.2039 \\
\hline \multicolumn{3}{|l|}{ Employment } \\
\hline Unemployed vs other & $0.24(-0.28$ to 0.75$)$ & 0.3620 \\
\hline Employed vs other & $-0.03(-0.39$ to 0.33$)$ & 0.8748 \\
\hline Marital status married vs other & $-0.04(-0.34$ to 0.57$)$ & 0.8410 \\
\hline Insurance: yes vs no & $-0.09(-0.42$ to 0.23$)$ & 0.5668 \\
\hline Education: high school or higher vs other & $0.17(-0.21$ to 0.54$)$ & 0.4078 \\
\hline
\end{tabular}

${ }^{*}$ High engagement, if total number of visits $\geq 2$; low engagement, if total number of visits $<2$

†Multivariable longitudinal linear regression model after adjusting for age, sex, preferred language, race, employment status, marital status, type of insurance, and years in school.

‡Based on interactive models where interactions between study group and follow-up visit (month) were included and tested.

\section{DISCUSSION}

Results of the study showed that both arms of the trial improved diabetes control as measured by HbAlc. There were significant improvements at 6 and 12 months, with the intervention group having a slightly better adjusted mean at each time point compared with the control group, though not statistically significant. All of the participants in this study were individuals who had not improved HbAlc in the 1.0 control program for at least 6 months prior to the enrollment in the trial. However, once participants enrolled in the trial for an additional 12 months, there were significant improvements in HbAlc. This finding provides some evidence that populations, such as low-income Mexican Americans, with diabetes and barriers related to social determinants of health may benefit from extended time and 
interventional supports to begin showing improvements in HbA1c.

The average HbAlc at enrollment for our study population was $10.31 \%$ (intervention group) and $10.26 \%$ (control group), both of which showed high levels of uncontrolled diabetes. Both groups showed a nearly half percentage point mean improvement in HbAlc at 12 months, but these values remain higher than clinical guidelines recommend. ${ }^{20}$ In our study, only $3.77 \%$ of the sample population fell within the guideline recommendations. ${ }^{34}$ Other interventions with populations facing high burden of disease and barriers to improvement from social determinants of health have shown similar findings ${ }^{35}$ and long-term supportive intervention strategies appear to be essential for driving HbAlc values to improved levels. ${ }^{36}$ CHWs are often part of the delivery team for these interventions. ${ }^{37}$

The results of this intervention are important because clinics and communities addressing diabetes management for patients with persistent uncontrolled diabetes need intervention and support options that can be adjusted, tried in combination, and used over time. Patients and providers can become disheartened when health is not improving, ${ }^{38}$ so having treatment options to try over time provides relief. This research provides options for low-income, Mexican American populations burdened with health disparities, which are lacking in the current literature.

\section{Limitations}

SyV 2.0 evaluation findings show that there were improved health outcomes across the intervention and control groups. The intervention participants did not see significantly greater improvements than the control participants in these outcomes. It is possible these physical and mental health outcomes require a longer term (eg, more than a year) to manifest into meaningful changes and observing these outcomes with a longer follow-up period may yield different results. The study timeline from funding to implementation was short and required simultaneous launch of the SyV 2.0 implementation and evaluation. Therefore, study recruitment and enrollment were occurring while workflows were being finalized in coordination with clinic partners to provide new services. As a result, there was a delay in providing services to intervention participants. The average window of time for participants to receive services was 6-8 months from date of referral, except for BHS, for which the average window of time for participants to receive services was within 2 months of their referral date. Due to these delays, participants did not receive a full 12 months of the SyV 2.0 intervention services, which also could have suppressed the intervention effect.

Another limitation was defining SyV 1.0 as the control group may have reduced the ability to detect the effect of SyV 2.0 compared with standard patient care, which does not include the Wagner Model of Care Coordination. Using a control group that receives a standard of care distinct from SyV 1.0 could better demonstrate the effect of the additional services provided by SyV 2.0. The study is also limited in its generalizability. The sample, largely unemployed and uninsured, was drawn from one region of the country from patients at two federally qualified health centers. Therefore, results should be interpreted with caution for Mexican American populations in different regions or with different demographic characteristics.

This study examined the effectiveness of the intervention as a whole and was not designed to evaluate the effectiveness of each specific component of the intervention. Future research should examine the effect of MTM and Behavioral Health Supports alone. We also recommend gathering systematic information about diabetes medications throughout a controlled trial to better account for real-time changes in medications. Additionally, future research may want to examine different doses of the intervention to identify what is the minimum amount that achieves impact across the study population. Additionally, future research could examine intervention effectiveness among underinsured populations in other geographic locations. Finally, future research should examine the impact of interventions on HbAlc among low-income populations that are delivered for longer than 12 months to better determine at what point statistically significant difference are achieved and for how long they are maintained.

\section{CONCLUSION}

In summary, this study found that a variety of intervention strategies provided under a chronic care management program over an extended period of time improved HbAlc outcomes at 6 and 12 months for low-income Mexican American participants with persistent uncontrolled diabetes. Providing additional intervention strategies, such as MTM, that are coordinated and delivered by clinical and community personnel, including CHWs, may help Mexican Americans with diabetes burdened with factors related to social determinants of health. The results provide insight into importance of participant engagement in a program and a few intervention strategies that contributed to improved diabetes management, which overextended periods of time may give providers options for supporting patients from populations burdened with health disparities. Future studies should continue to examine what intervention supports can most effectively address social determinant of health factors that create disparities in diabetes control to better achieve HbA1c standard clinical guidelines.

\section{Author affiliations}

${ }^{1}$ Department of Health Promotion and Behavioral Sciences, The University of Texas Health Science Center at Houston, School of Public Health, Brownsville Regional Campus, Brownsville, Texas, USA

${ }^{2}$ Division of Clinical and Translational Sciences, Department of Internal Medicine, McGovern Medical School, The University of Texas Health Science Center at Houston, Houston, Texas, USA 
${ }^{3}$ Biostatistics/Epidemiology/Research Design (BERD) Core, Center for Clinical and Translational Sciences (CCTS), The University of Texas Health Science Center at Houston, Houston, Texas, USA

${ }^{4}$ Department of Biostatistics and Data Science, School of Public Health, The University of Texas Health Science Center at Houston, Houston, Texas, USA ${ }^{5}$ Research and Evaluation, Health Resources in Action, Inc, Boston, Massachusetts, USA

${ }^{6}$ Department of Epidemiology, Human Genetics, and Environmental Sciences, School of Public Health, The University of Texas Health Science Center at Houston, Houston, Texas, USA

Acknowledgements The authors thank the participants for their involvement in the trial, the UTHealth SPH personnel and all affiliated clinics and partners for their collaborative work in implementing SyV 2.0 and Health Resources in Action, Inc. as the external evaluator. The authors also would like to recognize the funding for this trial from Methodist Healthcare Ministries. The authors also acknowledge grants from Methodist Healthcare Ministries of South Texas, Inc., the Corporation for National and Community Service (Social Innovation Fund Grant Number 14SIHTX001), and Valley Baptist Legacy Foundation.

Contributors BMR provided study concept. BMR, MHR, ML and LAM-B conceived the methodology and study design. BMR obtained funding. MH provided database and data management. MRS, JAG and CDA were data curation. MHR reviewed/ edited the manuscript. ML, AF and TX analyzed data and wrote the manuscript. $B M R, M L, M H, V P, M R S$, JAG and LAM-B are writing original draft preparation. BMR, MHR, ML and MH were involved in important intellectual content and read, and approved the final manuscript. BMR and MHR supervised.

Funding This material is based on work supported by the Corporation for Nationa and Community Service under Social Innovation Fund Grant Number 14SIHTX001. UTHealth SPH is a proud subgrantee of Methodist Healthcare Ministries' Sí Texas Project, a Social Innovation Fund (SIF) Program.

Disclaimer Opinions or points of view expressed in this document are those of the authors and do not necessarily reflect the official position of, or a position that is endorsed by, the Corporation for National and Community Service.

Competing interests None declared.

Patient consent for publication Obtained.

Provenance and peer review Not commissioned; externally peer reviewed.

Data availability statement Data are available on reasonable request. Deidentified participant data are available from the first author Belinda.M. Reininger@uth.tmc.edu.

Open access This is an open access article distributed in accordance with the Creative Commons Attribution Non Commercial (CC BY-NC 4.0) license, which permits others to distribute, remix, adapt, build upon this work non-commercially, and license their derivative works on different terms, provided the original work is properly cited, appropriate credit is given, any changes made indicated, and the use is non-commercial. See: http://creativecommons.org/licenses/by-nc/4.0/.

ORCID iD

Belinda M Reininger http://orcid.org/0000-0003-4446-9735

\section{REFERENCES}

1 American Diabetes Association. Where do I begin with type 2? American Diabetes Association, 2019.

2 Centers for Disease Control and Prevention. National diabetes statistics report. Atlanta, GA: Centers for Disease Control and Prevention, US Dept of Health and Human Services, 2017.

3 Unwin N, Whiting D, Roglic G. Social determinants of diabetes and challenges of prevention. Lancet 2010;375:2204-5.

4 Clark ML, Utz SW. Social determinants of type 2 diabetes and health in the United States. World J Diabetes 2014;5:296-304.

5 Centers for Disease Control and Prevention. Diabetes report card 2014. Atlanta, GA: Centers for Disease Control and Prevention, US Dept of Health and Human Services, 2015.

6 Rao Kondapally Seshasai S, Kaptoge S, Thompson A, et al. Diabetes mellitus, fasting glucose, and risk of cause-specific death. N Engl J Med 2011;364:829-41.

7 López L, Golden SH. A new era in understanding diabetes disparities among U.S. Latinos--all are not equal. Diabetes Care 2014;37:2081-3.
8 Gilmer TP, Roze S, Valentine WJ, et al. Cost-effectiveness of diabetes case management for low-income populations. Health Serv Res 2007;42:1943-59.

9 Wagner EH. Chronic disease management: what will it take to improve care for chronic illness? Eff Clin Pract 1998;1:2-4.

10 Nuckols TK, Keeler E, Anderson LJ, et al. Economic evaluation of quality improvement interventions designed to improve glycemic control in diabetes: a systematic review and weighted regression analysis. Diabetes Care 2018;41:985-93.

11 Powers MA, Bardsley J, Cypress M, et al. Diabetes self-management education and support in type 2 diabetes: a joint position statement of the American diabetes association, the American association of diabetes educators, and the Academy of nutrition and dietetics. Diabetes Care 2015;38:1372-82.

12 Klein HA, Jackson SM, Street K, et al. Diabetes self-management education: miles to go. Nurs Res Pract 2013;2013:581012.

13 Thompson T, McQueen A, Croston M, et al. Social needs and healthrelated outcomes among Medicaid beneficiaries. Health Educ Behav 2019;46:436-44.

14 Keene DE, Guo M, Murillo S. "That wasn't really a place to worry about diabetes": Housing access and diabetes self-management among low-income adults. Soc Sci Med 2018;197:71-7.

15 Gonzalvo JD, Hamm J, Eaves S, et al. A practical approach to mental health for the diabetes educator. AADE Pract 2019;7:29-44.

16 Stark Casagrande S, Cowie CC. Health insurance coverage among people with and without diabetes in the U.S. adult population. Diabetes Care 2012;35:2243-9.

$17 \mathrm{Hu}$ J, Amirehsani K, Wallace DC, et al. Perceptions of barriers in managing diabetes: perspectives of Hispanic immigrant patients and family members. Diabetes Educ 2013;39:494-503.

18 Testerman J, Chase D. Influences on diabetes self-management education participation in a low-income, Spanish-speaking, Latino population. Diabetes Spectr 2018:31:47-57.

19 Nam S, Chesla C, Stotts NA, et al. Barriers to diabetes management: patient and provider factors. Diabetes Res Clin Pract 2011;93:1-9.

20 American Diabetes Association. Health disparities among patients with diabetes can be improved by new approaches and insights Kirkwood M, 2017.

21 Witmer A, Seifer SD, Finocchio L, et al. Community health workers: integral members of the health care work force. Am J Public Health 1995:85:1055-8.

22 Centers for Disease Control and Prevention. Diabetes \& Mental Health Centers for Disease Control and Prevention. Atlanta, GA: Centers for Disease Control and Prevention, US Dept of Health and Human Services, 2018.

23 Casagrande SS, McEwen LN, Herman WH. Changes in health insurance coverage under the Affordable care act: a national sample of U.S. adults with diabetes, 2009 and 2016. Diabetes Care 2018;41:956-62.

24 Peek ME, Cargill A, Huang ES. Diabetes health disparities: a systematic review of health care interventions. Med Care Res Rev 2007;64(5 Suppl):101S-56.

25 Division of Diabetes Translation At A Glance Centers for Disease Control and Prevention. National center for chronic disease prevention and health promotion (NCCDPHP). Atlanta, GA: Centers for Disease Control and Prevention, US Dept ofHealth and Human Services, 2019

26 Olivarez E. Regional healthcare partnership (RHP) plan. Texas HealthcareTransformation and quality improvement program, 2012.

27 Fisher-Hoch SP, Vatcheva KP, Laing ST, et al. Missed opportunities for diagnosis and treatment of diabetes, hypertension, and hypercholesterolemia in a Mexican American population, Cameron County Hispanic cohort, 2003-2008. Prev Chronic Dis 2012;9:110298

28 Coleman K, Austin BT, Brach C, et al. Evidence on the chronic care model in the new millennium. Health Aff 2009;28:75-85.

29 Epping-Jordan JE, Pruitt SD, Bengoa R, et al. Improving the quality of health care for chronic conditions. Qual Saf Health Care 2004;13:299-305.

30 Harris PA, Taylor R, Minor BL, et al. The REDCap Consortium: building an international community of software platform partners. $J$ Biomed Inform 2019;95:103208.

31 Han B, Enas NH, McEntegart D. Randomization by minimization for unbalanced treatment allocation. Stat Med 2009;28:3329-46.

32 R Foundation for statistical Computing. $R$ : a language and environment for statistical computing $R$ core team. Vienna, Austria, 2015.

33 SAS. SAS® 9.4 SAS Institute Inc. Cary, NC: SAS Institute Inc, 2013.

34 American Diabetes Association. Standards of Medical Care in Diabetes-2019 Abridged for Primary Care Providers. Clin Diabetes 2019;37:11-34 
35 Gonzalez-Zacarias AA, Mavarez-Martinez A, Arias-Morales CE, et al. Impact of demographic, socioeconomic, and psychological factors on glycemic self-management in adults with type 2 diabetes mellitus. Front Public Health 2016;4:195.

36 Davies MJ, Heller S, Skinner TC, et al. Effectiveness of the diabetes education and self management for ongoing and newly diagnosed (DESMOND) programme for people with newly diagnosed type 2 diabetes: cluster randomised controlled trial. BMJ 2008;336:491-5.
37 Association of Diabetes Educators. Community health workers in diabetes management and prevention American. American Association of Diabetes Educators, 2015.

38 Halbesleben JRB, Rathert C. Linking physician burnout and patient outcomes: exploring the dyadic relationship between physicians and patients. Health Care Manage Rev 2008;33:29-39. 